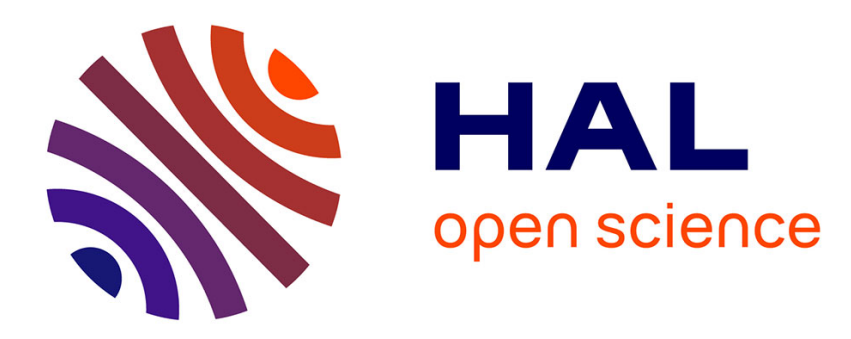

\title{
Validation of an effervescent spray model with secondary atomization and its application to modelling of a large-scale furnace
}

\author{
Jakub Broukal, Jiří Hájek
}

\section{- To cite this version:}

Jakub Broukal, Jiří Hájek. Validation of an effervescent spray model with secondary atomization and its application to modelling of a large-scale furnace. Applied Thermal Engineering, 2011, 10.1016/j.applthermaleng.2011.04.025 . hal-00762972

HAL Id: hal-00762972

https://hal.science/hal-00762972

Submitted on 10 Dec 2012

HAL is a multi-disciplinary open access archive for the deposit and dissemination of scientific research documents, whether they are published or not. The documents may come from teaching and research institutions in France or abroad, or from public or private research centers.
L'archive ouverte pluridisciplinaire HAL, est destinée au dépôt et à la diffusion de documents scientifiques de niveau recherche, publiés ou non, émanant des établissements d'enseignement et de recherche français ou étrangers, des laboratoires publics ou privés. 


\section{Accepted Manuscript}

Title: Validation of an effervescent spray model with secondary atomization and its application to modelling of a large-scale furnace

Authors: Jakub Broukal, Jiři Hájek

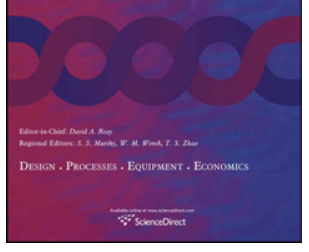

PII:

S1359-4311(11)00223-7

DOI:

10.1016/j.applthermaleng.2011.04.025

Reference:

ATE 3521

To appear in: Applied Thermal Engineering

Received Date: 15 November 2010

Revised Date: 7 April 2011

Accepted Date: 12 April 2011

Please cite this article as: J. Broukal, J. Hájek. Validation of an effervescent spray model with secondary atomization and its application to modelling of a large-scale furnace, Applied Thermal Engineering (2011), doi: 10.1016/j.applthermaleng.2011.04.025

This is a PDF file of an unedited manuscript that has been accepted for publication. As a service to our customers we are providing this early version of the manuscript. The manuscript will undergo copyediting, typesetting, and review of the resulting proof before it is published in its final form. Please note that during the production process errors may be discovered which could affect the content, and all legal disclaimers that apply to the journal pertain. 


\title{
Validation of an effervescent spray model with secondary atomization and its application to modelling of a large-scale furnace
}

\author{
Jakub Broukal (corresponding author), Jiří Hájek \\ Institute of Process and Environmental Engineering, Faculty of Mechanical Engineering, Brno University of \\ Technology, Technická 2896/2, 61669 Brno, Czech Republic, tel.: +420 54114 2368, fax: +420 541142372 \\ broukal@upei.fme.vutbr.cz
}

The present work consists of a validation attempt of an effervescent spray model with secondary atomization. The objective is the simulation of a $1 \mathrm{MW}$ industrial-type liquid fuel burner equipped with effervescent spray nozzle. The adopted approach is based on a double experimental validation. Firstly, the evolution of radial drop size distributions of an isothermal spray is investigated. Secondly, the spray model is tested in a swirling combustion simulation by means of measured wall heat flux profile along the flame.

In the first part of the paper,both experimentsare described along with the measuring techniques. Drop sizes and velocities measured using a Dantec phase/Doppler particle analyser are analysed in detail for six radial positions. Local heat fluxes are measured by a reliable technique along the furnace walls in a large-scale watercooled laboratory furnace.

In the second part Euler - Lagrange approach is applied for two-phase flow spray simulations. The adopted spray model is based on the latest industrially relevant (i.e. computationally manageable) primary and secondary breakup sub-models complemented with droplet collision model and a dynamic droplet drag model.Results show discrepancies in the prediction of radial evolution of Sauter mean diameter and exaggerated bimodality in drop size distributions. A partial qualitative agreement is found in radial evolution of drop size distributions. Difficulties in predicting the formation of small drops are highlighted. Comparison of the predicted wall heat fluxes and measured heat loads in swirling flame combustion simulation shows thatthe absence of the smallest droplets causes a significant elongation of the flame.

Keywords: drop-size distribution, effervescent atomization, modelling, spray combustion

\section{Introduction}

Spray combustion is one of the main ways to gain energy in the power and process industries. A great deal of effort is constantly being put into understanding of the fundamental phenomena and processes governing spray formation and swirling combustion. These efforts are motivated by the need to achieve better performance, lower emissions and longer lifetime of furnaces and combustors in various industrial applications.

For combustion purposes, effervescent atomizers are gaining on popularity. They were first introduced by Lefebvre and his colleagues in the late 1980s [1]. The spray formation process in this type of atomizers does not rely solely on high liquid pressure and aerodynamic forces, instead a small amount of gas (usually air) is introduced in the liquid before it exits the atomizer and a two phase flow is formed (Figure 1) [2]. When the mixture exits through the nozzle, pressure suddenly drops, which causes fast expansion of gas bubbles andbreakup of the liquid fuel into droplets. This breakup mechanism allows to use lower injection pressures and larger nozzle diameters without compromising the drop-size distribution [3].

\subsection{Wall heat flux distribution}

When designing a furnace or combustor one of the most important parameters is the distribution of wall heat fluxes, especially on cooled walls (heat exchanging areas). In the last two decades, a number of works can be found wherewall heat fluxes are investigatedeither experimentally (e.g. [4])or numerically using computational fluid dynamics (CFD) tools (e.g. [5]). Measurement of local heat loads in industrial conditions is however possible only using special heat flux probes that cannot provide reliable detailed data covering the whole heat transfer area, but only a limited number of discrete points. Additionally, industrial units typically have only rough estimates of the instantaneous total heat transfer rate (e.g. $\pm 4 \%$ in[6]).

The measurement of wall heat fluxes was traditionally connected mainly to the identification of fouling and slagging, especially in pulverised-coal boilers. Therefore many of the existing probes are designed to operate in harsh environments. In laboratory experiments the measured heat flux data are naturally more reliable than in 
industrial combustors. Even though, the accuracy of available measurement methods is on the order of several percent. E.g. for the measurements of thermal irradiation flux are often used ellipsoidal radiometers (accuracy $\pm 5 \%$ ) and water-cooled circular foil heat flux radiometers (accuracy $\pm 2 \%$ )[4]. The $\pm 2 \%$ accuracy is about the best one can achieve with heat flux metering probes. However, as reported in[4], differences of values measured by these two methods may reach up to $12 \%$, thus decreasing the credibility of point heat flux measurements.

On the other hand, the measurement of heat transfer rate in a segmental experimental combustion chamber with water cooling may provide appreciably more precise values, as shown in [5]. This is also the method adopted in the present work.

\subsection{Swirling nopremixed combustion}

The problem complexity is further enhanced when taking into consideration, that the vast majority of power burners use swirl stabilizers, as discussed in[7].The turbulent swirling flow is difficult to model even alone and when chemistry and radiation are added, the resulting problem becomes very complex. In the present,proven approaches that can deal with these complex flows include Large Eddy Simulations (LES) or direct numerical simulations coupled with advanced chemistry models, e.g.[8].Those very detailed results come at a price of extremely high computational demands, which are generally unacceptable in industrial applications. That is why even authors of these advanced LES studies are unsure whether the use of LES strategy will in the future prevail over unsteady Reynolds-averaged Navier-Stokes (RANS) approach[8].

More research is therefore needed to find simpler time-effective numerical models from the RANS or unsteady RANS class for the prediction of swirling nonpremixed flames that would yield practically relevant results.The issue of local wall heat flux prediction in swirling combustor has been recently investigated for the case of methane swirling combustion in [5] and it has been shown, that local wall heat flux predictions are very sensitive to the choice of models used to describe the physical and chemical processes occurring in flames. Results in [5]provide guidelines for the selection of several sub-models in computations of swirling nonpremixed gas flames.

\subsection{Spray modelling}

The presence of spray droplets in swirling spray combustion further increases complexity of predicting these flames. Clearly, to minimize the uncertainties and errors that are caused by numerical representation of sprays, appropriate spray models need to be found and validated.

At the present time, two predominant methods for numerical spray representation are used: the Euler Euler and Euler - Lagrange approach[9]. The first approach is computationally demanding and so far is used almost exclusively for spray formation investigations without combustion as for example in[10,11]. The latter approach is less demanding and allows employment in combustion applications as for example [12,13]. The relative simplicity and low computational costs of the Euler - Lagrange approach are compensated by the need to find or develop appropriate sub-models for primary breakup (to determine initial droplet parameters like diameter and velocity and theirangular variations) and secondary breakup (breakup of droplets that occurs farther from the nozzle) as well as for all other processes concerning the droplets, like momentum, heat and mass transfer in the evaporating spray.

The most crucial step when modelling a spray in the Euler - Lagrangian framework is the primary breakup. The model responsible for this process should ideally provide us with an initial drop size distribution, velocity distribution and mass flow rates, all dependent on spray angle. Available advancedmethods that try to approach this idealized model include for example the Maximum Entropy Formalism (MEF) or Discrete Probability Function (DPF) method.These two methods are able to provide us with drop size and velocity distributions (in the case of DPF only with drop size distribution) and can also, to some extent, predict multimodal distributions, as demonstrated for example in[14]. Unfortunately both havealso significant drawbacks.MEF requires two representative drop diameters and good predictions are achieved only after adjustments of the model parameters in order to fit experimental data. In the case of DPF, probability density functions of the fluctuating initial conditions are needed. Such fluctuations can be caused by a number of factors, some of which are vibrations of the atomizer, fluctuations in liquid delivery rate, fluctuations in liquid properties (in the case of non-homogenous liquids), fluctuations in exit velocity, etc.However, at the present time we are not able to measure these functions[3].So far these drawbacks disqualify such methods from being widely used in industrial applications, although they represent a promising research direction.

Since advanced models able to predict the whole range of diameters are not applicable at the moment, simpler primary breakup models are being used. These models usually focus on predictions of a single representative diameter. Papers can be found (e.g. [15]) where authors propose empirical correlations between the representative diameter and various physical conditions based on measured data. Such correlations are unfortunately 

applications, operating conditions are not constant, therefore more flexible models need to be employed. To overcome this obstacle, analytical formulas derived from first principles are needed.

One of the analytical approaches to describe primary atomization was performed by Senecal [16]. He relates to the pioneering work on jet disintegration by Weber [17]. In his work he investigates liquid sheet atomization and develops the so called LISA (Linearized Instability Sheet Atomization) model. Primary atomization of effervescent atomizers has been assessed by Lund [18]. The approach of Lund is, similarly to the previous case, based on Weber's work [17], but when formulating the model a simpler instability analysis is used. An improvement of Lund's model is proposed by Xiong [19], by applying the more rigorous Senecal's instability analysis.

Once the initial drop diameter is obtained, we are interested in how will the drop change in space and time. When primary breakup model provides a single diameter, the expectation from the secondary breakup model is to create an approximation of the actual drop size distribution. There are two main branches of secondary breakup models. The first branch is based upon Taylor's analogy between an oscillating and distorting droplet and a spring mass system [20] and it is called Taylor Analogy Breakup (TAB) model (used for example in [16]). The second model branch is based on the wave breakup model of Reitz [21]. Here the drop breakup is considered to be induced by the relative velocity between the liquid and gas phase. The relative velocity causes the growth of KevinHelmholtz instabilities which are responsible for the final breakup. The model was used for example in [22].

There are also other approaches to secondary breakup modelling. Xiong [19] employs Cascade Analogy Breakup model proposed by Tanner [23] to simulate an effervescent atomizer.The secondary breakup model based on Fokker - Planck equation proposed Apte [24] is adopted by Vuorinen [25]. These recent models however yet have to be extensively validated and thus have not reached wide acceptance.

\subsection{Spray model validations}

In the area of combustion, spray models are usually validated based on their ability to predict the Sauter Mean Diameter (SMD). This is a very rough approach as follows from the discussion in the preceding section. Significantly more detailed information would be needed to make really sensible validations. Namely, data about radial (or equivalently depending on spray angle) distribution of droplet size and velocity would be desirable, especially for the case of large nozzles in industrial burners.

Currently, spray model validation studies compare numerical results with experiments usually only in terms of axial SMD evolution. This validation concept is adopted for example in [15,19,24,26,27].Apte [24] predicts axial SMD evolution in a diesel engine using a proposed hybrid particle-parcel model coupled with a LES solver,but only a single experimental SMD value is used in the comparison. A model for atomization of viscous and non-Newtonian liquids in an air-blast atomizer is described by Aliseda et al. [26]. The model was validated in terms of axial SMD evolution and good agreement has been achieved in the spray region farther from certain distance downstream from the nozzle. Tembley[27] used MEF to predict drop size distribution in ultrasonic atomizers. He developed a model able to predict initial drop size distribution as well as how does the distribution change along the spray axis. However, this model only predicts the overall drop size distribution of a spray cross-section at a specified axial distance.

Recently, few papers can be found that address the issue of radial drop size distribution and radial SMD evolution. Park et al. [22] employed the wave breakup model to investigate biodiesel spray in various fuel and ambient conditions in terms of axial and radial SMD evolution. Along with axial SMD evolution, also radial SMD evolution was reported. Unfortunately, only three radial SMD were disclosed.In [28] a new Euler - Euler spray model is presented and applied to water air-assisted atomization. Radial drop diameter evolution is predicted at various axial positions, but regrettably, no comparison with experimental data has been made. This illustrates the pressing need for validated spray models that would include sufficient information for an informed choice of models by CFD analysts in the industry.

Although many research papers have been published about atomization and drop breakup, only little attention is given to radial SMD or more detailed spatial drop-size distribution, especially in effervescent atomizers. The present work suggeststhat the drop diameter evolution in radial direction plays an important role in combustion applications and spray models should be able to predict this feature.

The approach adopted in the present work is the Euler - Lagrange with improved Lund's model (according to Xiong [19]) applied to account for primary breakup. The secondary breakup is then governed by Reitz's wave model [21]. The motivation of the current study is the prediction of radial drop-size distributions and double experimental validation by isothermal spray measurement and precise local wall heat flux measurement in a largescale laboratory combustion facility. 


\section{Experiments}

This workreports data obtained from two different experiments. In the first experimentthe effervescent atomizer was analysedin terms of radial drop-size distribution. The purpose of the second experiment was to collect local wall heat flux data in a large-scale combustion chamber (for duties up to $2 \mathrm{MW}$ ). Both experimental results are later compared with data obtained from numerical simulations.

\subsection{Spray measurement and data processing}

The measured spray of extra-light fuel-oil was generated using the effervescent atomizer in a vertical position described in [29] as configuration E38. The atomizer had a single orifice (2.5 $\mathrm{mm}$ in diameter) and consisted of a cylindrical body with an inserted aerator tube. The aerator had 80 holes, each $1 \mathrm{~mm}$ in diameter, through which the air entered into the liquid.The volume of the mixing chamber inside the aerator tube is given by the length downstream of the last row of air holes $(35 \mathrm{~mm})$ and the internal diameter of the aerator tube (14 mm). The oil density, dynamic viscosity and surface tension was $874 \mathrm{~kg} / \mathrm{m}^{3}, 0.0185 \mathrm{~kg} / \mathrm{ms}$ and $0.0297 \mathrm{~N} / \mathrm{m}$ respectively. The atomizing pressure was $0.3 \mathrm{MPa}$ which corresponded to an oil mass flow rate of $21.8 \mathrm{~g} / \mathrm{s}$ and atomizing air mass flow rate of $2.18 \mathrm{~g} / \mathrm{s}$ (gas-liquid ratio of 10\%). Drop sizes and drop velocities were measured using a Dantec phase/Doppler particle analyser (P/DPA) in 6 radially equidistant sampling points at $150 \mathrm{~mm}$ from the atomizer orifice. The drawing in Figure 2shows the measurement pointsin a half-angle of the spray (between the axis and the farthermost measurement point).A detailed description of the measurement can be found in [29]. At each of the six measurement points more than 30,000 particles were sampled, leading to a total of approximately 200,000 sampled particles.

For the purpose of data analysis a software with graphical user interface was created using MATLAB programming environment. The software was designed for the processing of experimental data from multiple measuring points as generated by the measuring device. The spray cone was supposed to be symmetrical. The circular cross section of the spray cone at the measurement distance was divided into annular areas corresponding to each measurement point (clearly, for the innermost measurement point the area was circular). The drop-size distribution in each measurement point was assumed to be identical for the whole corresponding area (piecewise constant). From the analysis detailed data were acquiredabout the total drop-size distribution as well as about the radial evolution of the drop-size distribution as shown in Figure 3.

A similar discrepancy, as seen in the work of Babinski and Sojka [3], has been found between measured and calculated mass flow rates of the atomized liquid. The calculated mass flow rate was approximately $60 \%$ smaller. Such behaviour is probably caused by a non-zero error rate of the measurement technique causing rejection of particles.

The number-based drop-size distributions in several of the sampling points in the measured spray were bimodal. The distributions obtained from the measurement points close to the atomizer centreline exhibited unimodal behaviour, but bimodality manifested itself as the distance from the centreline increased (see Figure 3). The overall number-based drop-size distribution is slightly bimodal.

The volume-based drop-size distributions for respective measurement points on the other hand do not display bimodality, but they generally exhibit discontinuities in the large drop size end of the distribution. These discontinuities might be again caused by the rejection of particles during measurement or by insufficient sampling time. The second option would mean that the number of sampled particles is not high enough to provide statistically meaningful results.Cleary [30] and Jedelský [31] both sample 20,000 particles per measuring point while Liu samples 50,000 to 100,000 droplets per measuring point [32]. A definitive answer to this issue is unfortunately unavailable and a more detailed experimental study would be necessary to provide it.

\subsection{Large-scale combustion facility}

Wall heat fluxes in combustion chambers, furnaces and boilers are one of the most important parameters in process and power applications. The distribution of local heat flux across heat exchanging areas is of special interest due to material strength and durability implications. It is therefore very important to have experimental data for validation of computational predictions.In this worklocal wall heat flux data were obtained from a swirling spray combustion experiment in the test facility locatedat the Institute of Process and Environmental Engineering of Brno University of Technology (Figure 4).

The combustion experiment has been performed in a water-cooled horizontal combustion chamber $(1 \mathrm{~m}$ internal diameter and $4 \mathrm{~m}$ length). The shell of the chamber is divided into seven sections; each of which has a separate water inlet and outlet and is equipped with a water flow meter and temperature sensors, allowing for accurate local heat transfer rate measurement along the flame as described in[5]. The experimental facility is 
described in detail in[7,33]. The fuel was atomized using a single nozzle effervescent atomizer described in the previous section.In Figure 5 is a simple sketch of the burner and combustion air supply duct.

In order to reduce liquid fuel consumption (due to limited storage capacity), the combustion chamber was preheated using natural gas. The liquid fuel and air operating parameters and propertiesare reported inTable 1. Thermal duty in the experiment was set to $928.7 \mathrm{~kW}$; HHV of the liquid fuel was $42.6 \mathrm{MJ} / \mathrm{kg}$.Stabilization of the experiment was established with respect tolocal wall heat fluxes in all sections of the furnace, which were monitored continuously. After reaching a steady state, the measurement procedure began and data were collected for about 30 minutes.

\section{Modelling}

This section outlines the models applied in the computational part of this work.The objective is to evaluate models that are routinely applied in the industrial practice due to their computational manageability. This implies that tradeoffs between accuracy and computational demands were required in the selection of all sub-models (for turbulence, chemistry, radiation, spray formation and secondary breakup).

The modellingwork includes two separate simulations. First is a validation of the primary and secondary atomization model in a setup that mimics conditions during the spray measurements.Numerical drops are sampled in 6 areas corresponding to the experimental measurement points and emphasis is placed on the prediction of drop size distributions in those radial locations and their comparison with experimental results. In the second simulation the same spray model is used to compute the reacting flow in a large-scale oil-fired combustion chamber, focusing on wall heat flux predictions.

The computations were performed in Ansys Fluent code[34].To track the liquid particles Discrete Phase model (DPM) has been used, which is based on the Euler - Lagrange approach. The particles were tracked in an unsteady fashion. The particle time step size was set to $0.0001 \mathrm{~s}$ and Step Length Factor (SLF) to 15. The SLF controls the accuracy of particle trajectory computation and the chosen value is equal to that recommended in [35].

To predict the particle trajectory, one has to integrate the force-balance equation, which can be written (for the $x$ direction in Cartesian coordinates) as follows:

$$
\frac{d u_{p}}{d t}=F_{D}\left(u-u_{p}\right)+\frac{g_{x}\left(\rho_{l}-\rho_{g}\right)}{\rho_{l}}
$$

where $u_{p}$ is the particle velocity, $u$ the surrounding air flow velocity, $g_{x}$ gravity in $x$ direction, $\rho_{l}$ and $\rho_{g}$ are the densities of the liquid and gaseous phase. $F_{D}\left(u-u_{p}\right)$ is the drag force per unit particle mass.

$$
F_{D}=\frac{18 \mu_{g} C_{D} \operatorname{Re}_{r e l}}{24 \rho_{l} d^{2}}
$$

where $d$ is drop diameter, $\mu_{g}$ is the molecular viscosity of the fluid (air), $C_{D}$ is the drag coefficient (will be defined in the following sections) and $\mathrm{Re}_{r e l}$ is the relative Reynolds number defined as

$$
\operatorname{Re}_{r e l}=\frac{\rho d\left|u_{p}-u\right|}{\mu_{g}} .
$$

In order to take into account the turbulent flow effects on particle motion, the Discrete Random Walk (DRW) model has been applied. Time scale constant in the DRW model was set to 0.15 , which is appropriate for the $k-\varepsilon$ turbulence model according to [34] and references therein. The DRW model simulates interactions of a particle with a succession of discrete stylized fluid phase turbulent eddies.

\subsection{Spray model}

Ansys Fluent offers a variety of atomizer models and injections. Unfortunately, it does not offer any atomizer model that corresponds to the atomizer used in the experiments; therefore it was decided to use a so-called solid coneinjection instead. The spray is axially symmetrical and therefore, to reduce computational costs, only a $30^{\circ}$ cylinder section has been meshed using 15,720 hexahedral cells, with approximately 50, 40 and 8 grid nodes in the axial, radial and tangential directions respectively. The dimensions of the cylindrical computational domain were as 
follows: $800 \mathrm{~mm}$ height and $400 \mathrm{~mm}$ diameter. The domain was filled with air and the spray originated on the centreline $200 \mathrm{~mm}$ from the air inlet base of the cylinder(seeFigure 6). The spray was injected from a small circular area of diameter $2.5 \mathrm{~mm}$ representing the actual nozzle orifice. In the position of measuring location $150 \mathrm{~mm}$ downstream from the injection a series of concentric annular control surfaces have been set up that enabled the virtual measurement of droplets. A small air co-flow $(0.5 \mathrm{~m} / \mathrm{s})$ was introduced to improve solution stability, periodic boundary condition was enforced on the sides of the $30^{\circ}$ cylinder section in order to obtain meaningful results for the whole cylinder and finally a pressure outlet condition was used for flow exit. A porous zone was introduced at the end of the domain to preventpossible backflow. The backflow would not have any effect on the spray in the analysed locations due to the large size of the domain, but it is undesirable as it causes problems in simulation convergence. Turbulence was modelled using $k-\varepsilon$ realizable model [36] with the original values of model constants, namely $\mathrm{C}_{1 \varepsilon}$ and $\mathrm{C}_{2}$ equal to 1.44 and 1.9 respectively, and turbulent Prandtl numbers $\sigma_{\mathrm{k}}$ and $\sigma_{\varepsilon}$ equal to 1 and 1.2 respectively.

The spray measurement was performed in vertical downward configuration and the influence of gravity on drop velocity in the sampling location wastherefore negligible.

\subsubsection{Primary breakup}

As pointed out in [19], in numerous experimental observations of effervescent atomizers it was concluded, that the primary atomization of the liquid undergoes three stages. First, assuming that the two phase flow in the nozzle is annular, an annular sheet forms and breaks up into cylindrical filaments. Second, the filaments break into ligament fragments. Finally, the ligament fragments stabilize to form individual droplets. In this work, a one-dimensional breakup model based on Lund[18] and further developedin[19]is used to predict the spray SMD after primary breakup. The model assumes that the annular liquid sheet breaks into several cylindrical filaments with almost the same diameter as the thickness of the annular sheet. The filaments then break into ligament fragments at the wavelength of the most rapidly growing wave and each fragment only forms one drop.

Regrettably, the model does not give any information about the initial droplet velocity nor about the spray angle. These parameters therefore need to be estimated alternatively. The initial particle velocity was approximated as $154 \mathrm{~m} / \mathrm{s}$ using the formula

$w_{2}=\sqrt{2 x p_{1} v_{g 1} \frac{K}{K-1}\left[1-\left(\frac{p_{2}}{p_{1}}\right)^{\frac{K-1}{K}}\right]+2(1-x) v_{l}\left(p_{1}-p_{2}\right)+w_{1}^{2}}$

derived by Jedelský and Sláma in Appendix 2 of [29], where $w_{2}$ is the discharge velocity, $w_{1}$ is the velocity of the two-phase mixture in the mixing chamber, $p_{2}$ is the pressure at the discharge orifice, $p_{l}$ is the pressure inside the mixing chamber, $v_{l}$ is the specific volume of the liquid phase, $v_{g l}$ is the specific volume of the gas phase inside the mixing chamber, $x$ is the gas-liquid ratio and $K$ is the isentropic exponent of the two-phase mixture. The spray angle $18.44^{\circ}$ was determined from the experimental measurement (Figure 2). Lund's model is entirely based on first principles and its variations are often adopted due to its simplicity and satisfactory predictions [19,37]. The predicted SMD is later used as the initial diameter of injected droplets during the numerical simulation.

\subsubsection{Secondary breakup}

Secondary breakup was taken into account by including the wave model by Reitz [21]. This model was developed for high-Weber-number flows and considers the breakup to be induced by the relative velocity between the gas and liquid phases. The model assumes that the time of breakup and the resulting droplet size are related to the fastestgrowing Kelvin-Helmholtz instability. The wavelength and growth rate of this instability are used to predict details of the newly-formed droplets. This model is also often used in the area of internal combustionengines[38]. The wave model requires two parameters. The first parameter $\left(C_{l}\right)$ affects the radius of the child droplets and has been set to 0.61 based on the work of Reitz [21]. The breakup time scale is governed by the second parameter $\left(C_{2}\right)$, which can range from 1 to 60 depending on the spray characteristics. The parameter $C_{2}$ is a measure of how quicklythe parent droplet will lose mass. A larger value means that it takes longer for a droplet to lose a given amount of mass. In their work Liu et al. [39] recommended 1.73 as a default value. In this work, together with the default value, two other values are tested, namely $C_{2}=2.5$ and $C_{2}=10$.

By using this model it is assumed, that atomization occurs only in the region close to the spray nozzle, since farther downstream the relative velocity decreases due to aerodynamic drag and the model no longer predicts any breakup. In reality, secondary breakup occurs even further downstream from the nozzle.However, for the 
current case a reasonable assumption is made that the highest rate of drop breakup is concentrated in the region close to the spray nozzle and therefore breakup in low-velocity regions is neglected.

\subsubsection{Droplet collision}

The algorithm of O'Rourke [40] was used to determine the outcome of drop collisions. Rather than calculating exact trajectories to see if parcel paths intersect, O'Rourke's method is a stochastic estimate of collisions.Two particles can collide only if they are in the same computational cell. Once it is decided that two parcels of droplets collide, the algorithm further determines the type of collision. Only coalescence and bouncing outcomes are considered. The probability of each outcome is calculated from the collisional Weber number $\left(W e_{c}\right)$ and a fit to experimental observations. Here,

$W e_{c}=\frac{\rho U_{r e l}^{2} D}{\sigma}$,

where $U_{r e l}$ is the relative velocity between two droplets, $D$ is the arithmetic mean diameter of the two drops, $\rho$ is the liquid density and $\sigma$ the surface tension.

The O'Rourke algorithm does not take into account the shattering outcome of the collision, which occurs at high Weber numbers. This drawback does not necessarily need to be significant, as the Weber number is expected to decrease rapidly[15].However, this can cause absence of small droplets in the region close to the spray nozzle.

\subsubsection{Droplet drag model}

Accurate determination of droplet drag coefficients is crucial for accurate spray modelling. Ansys Fluent provides a method that determines the droplet drag coefficient dynamically, accounting for variations in the droplet shape. The shape of drops is often assumed to be spherical, but in the case of high Weber numbers, this assumption can distort the final results. The dynamic drag model accounts for the effects of droplet distortion, linearly varying the drag between that of a sphere and a value of 1.54 corresponding to a disk. The drag coefficient is given by

$C_{D}=C_{D, s p h}(1+2.632 y)$,

where $C_{D, s p h}$ is the drag coefficient of a sphere and $y$ is the distortion, as determined by the solution of

$\frac{d^{2} y}{d t^{2}}=\frac{C_{F} \rho_{g} u^{2}}{C_{b} \rho_{l} r^{2}}-\frac{C_{k} \sigma}{\rho_{l} r^{3}} y-\frac{C_{d} \mu_{l}}{\rho_{l} r^{2}} \frac{d y}{d t}$,

where $t$ is time, $r$ the undisturbed drop radius, $\mu_{l}$ the drop viscosity and $C_{F}, C_{k}, C_{b}, C_{d}$ are dimensionless constantsequal to $1 / 3,8,0.5$ and 5 , respectively, as determined by O'Rourke and co-workers in [41].

\subsection{Combustion model}

The swirling combustion simulation wasperformed using commercial CFD code Ansys Fluent as well. The main goal of these simulations was to predict heat fluxes absorbed by the cylindricalwater-cooled combustion chamber walls. For the purposes of numerical analysis a mesh was constructed in the software Gambit (Figure 7). The total number of computational cells (97\% of which are hexahedral) was nearly 1,200,000, with approximately 200, 65 and 135 grid nodes in the axial, radial and tangential directions respectively. Four boundary conditions were applied - mass flow inlet (for combustion air, seeTable 1), pressure outlet, prescribed temperature on the water-cooled walls $\left(80^{\circ} \mathrm{C}[42]\right)$ and adiabatic condition for the remaining walls.

The flow field was obtained by solving the unsteady Reynolds-averaged Navier-Stokes equations together with turbulent mixing controlled eddy breakupmodel[43]to account for turbulence chemistry interactions. Turbulence was modelled using the $k-\varepsilon$ realizable modelused for the isothermal spray simulation. In combustion chambers, the main mechanism of heat transfer is radiation. As shown by Baek [44], the discrete ordinates model offers good results and reasonable computational demand. The absorption coefficients were obtained using the domain-based approach of the weighted sum of grey gases model, which reportedly gives good prediction for heat transfer according to [45].The fuel droplets were modelled as discrete Lagrangian entities - particles. The atomized fuel was modelled using the models specified in section 3.1. The operating conditions were identical to the 
combustion experiment (Table 1) and gravity was taken into account, since the combustion chamber is in horizontal position.

\subsubsection{Evaporation}

As the droplets are heated up by the reaction heat, mass transfer occurs between the discrete Lagrangian entities (fuel droplets) and the continuous gas phase. To take into account such interaction between phases, mass source terms are introduced to the gas phase in appropriate cells, whereas the mass and temperatureof droplets areadjustedsimultaneously. The evaporative mass fluxes are governed by gradient diffusion, with the flux of droplet vapour into the gas phase related to the difference in vapour concentration at the droplet surface and the bulk gas. No flow inside the droplet is considered and droplet properties such as temperature and density are considered to be uniformover the droplet volume.

\section{Results and discussion}

In the following subsections results will be presented and compared with experimental data. Shortcomings will be mentioned and their sources will be discussed. First, the results of the isothermal effervescent spray simulation will be presented and discussed, followed by the combustion simulation of large-scale combustor.

\subsection{Spray simulations}

The initialization, motion and breakup of droplets and their interaction with the gaseous phase weregoverned by sub-models presented in section 3. For this isothermal non-reactive simulation the sub-model for droplet evaporation was disabled.The initial droplet diameter predicted by the primary atomization model was $225.2 \mu \mathrm{m}$.

Data on the resulting numerical spray were collected in a similar manner as in the experiment. The only difference was that data were collected from concentric annular areas and not points as in the physical experiment. The raw data were imported into Matlab environment and further analysed and visualized in the same way as the experimental data.The objective was to investigate predictive capabilities of the selected spray model in terms of radial and overall drop size distributions.

Form Figure 8 it is apparent that the model in all three cases (as defined in section 3.1.2) fails to predict drop diameters smaller than approximately $31 \mu \mathrm{m}$ and on the other hand the maximal predicted diameter is greater $(245 \mu \mathrm{m})$ than the maximal experimentally measured diameter $(194 \mu \mathrm{m})$. This may be caused by the wave model, which does not predict any breakup at low Weber numbers. Additionally, drop coalescence is not diminished in these conditions,thus increasing the drop diameter in spray regions with low Weber number. Also, for all the three cases the maximal diameter decreases while moving radially to the spray peripheral region, which is contradictory to the experimental results.

The overall SMD obtained from simulations $(67.6 \mu \mathrm{m})$ under predicts the experimental value $(83.2 \mu \mathrm{m})$. This mismatch is opposite than the one reported in [37], where the simulated SMD over predicted experimental SMD.

The radial evolution of predicted and measured SMD is shown in Figure 9. The experimental measurement shows that SMD is smallest at the spray core and then increases when moving radially to the edge of the spray. The predicted SMD evolution is however different. At the spray core the biggest SMD value is predicted and SMD further decreases. After the third measurement point it remains almost constant. This discrepancy clearly shows the poor prediction of radial spray drop-size distribution regardless of the $C_{2}$ parameter value.

The comparison of radial evolution of the number-based drop-size distributions at the sampling locations $150 \mathrm{~mm}$ downstream from the atomizer (same as in the experiment)are shown in Figure 10. In the first three measuring points a shift towards the right hand side of the predicted distribution is observed for all three $C_{2}$ parameters. In addition,bimodal behaviour is predicted in all measurement points for the case $C_{2}=1.73$ and in the last two measurement points for the case $C_{2}=10$. The predicted drop sizes in the peripheral regions are also smaller than the experimentally measured values.

In Figure 11 are presented volume-based drop-size distributions corresponding to appropriate measuring points at the same locations as in the previous paragraph. Except for the measurement point on the spray axis $(\mathrm{r}=0 \mathrm{~mm})$, all three cases give very similar results and are relatively closer to the experimentally measured distribution than in the case of number-based distributions. In all measurement points the case $C_{2}=10$ has the "heaviest" tail, meaning it predicts the largest droplets. This is expected, since as mentioned in section 3.1.2 the higher the value of $C_{2}$, the slower the atomization process is. 
Figure 12 reports the comparison of overall drop-size distributions based on number and volume. Similarly as in Figure 10, bimodality is predicted in the case $C_{2}=1.73$ and also the "heavy" tail in the case $C_{2}=10$ is again apparent. The deficiency of numerical results is marked by the absence of small numerical drops.

The phenomenon of bimodality manifested itself in both experimental as well as in the simulated drop size distributions (mainly in the case $\mathrm{C} 2=1.73$ ). Such behaviour is not uncommon in spray applications and it would be a significantaid to be able to predict it. Bimodality, in some cases even multimodality, also raises the question about legitimacy of using a single representative diameters (e.g. SMD) to represent the drop size distributions.

For areally detailed analysis of the quality of the secondary breakup model,more experimental data at different axial locations would be desirable, but are unfortunately not available.

\subsection{Combustion simulation}

This section presents a comparison between experimentally obtained local heat transfer rates and numerical prediction.Although none of the three cases discussed in the previous sections can be claimed to be superior, in the combustion simulation the case $C_{2}=1.73$ has been used. The reason is that it captured the bimodality phenomena better with respect to the other cases. The numerical results are also compared with the results of authors' previously proposed model [46], where no breakup was taken into account and the particle diameters were initialized with a Rosin-Rammler drop size distribution, which was based on experimental results. The previous spray model was therefore based a priory on experimental data, which is not the case in this study.Despite the older results do not present a better alternative, they have been compared with the current simulation in order to point out someinteresting consequences.

Numerous experimental measurements have been performed in the last few years for the case of natural gas combustion in the same testing facility $[5,47]$. Repeatability of the applied heat flux measurements and accuracy of the method that measures heat extracted in individual sections of the furnace has been addressed in [47]. Overall, the method provides highly reliable and accurate data, unlike point measurements using heat flux probes as discussed in the Introduction.

In Figure 13it can be seen that the wall heat fluxes obtained from simulations do not agree well with the experimental measurements. The simulation peak occurs between the $5^{\text {th }}$ and $6^{\text {th }}$ section while the experiment suggests the peak is around the $4^{\text {th }}$ section. The simulation also under predicts the maximal wall heat flux. One of the reasons of these discrepancies is clearly the representation of the effervescent spray, whose drawbacks were discussed in the previous section. The figure suggests that the smallest drops might be missing and therefore it takes longer for the spray to evaporate and subsequently to burn, thus moving the flame farther downstream.

It is interesting that the predicted wall heat fluxes are quite close to the results obtained using author's previous model [35] despite significant differences in the spray representation. This may be caused by the fact that both spray representations suffer from significant deficiencies. At this point it is difficult to tell the reason of this occurrence, since also other phenomena involved in the simulation (turbulence, radiation, chemistry) present a great deal of uncertainty. Further examination is needed in order to determine the nature of this behaviour. Related work focusing on the case of natural gas combustion as documented e.g.in [5] shows these effects of other modelling options. Swirling combustion applications clearly present a very complex task for numerical modelling.

Another possible cause could be the simplification of the effervescent atomizer model. The simulations did not take into account the atomizing air exiting the atomizer nozzle together with the liquid drops. Although the flow rate of the atomizing air is very small compared to the combustion air $(0.5 \%)$, it might have important effects on the mixing process of the evaporated fuel with air. This issue is closely related to turbulence modelling, which has major effects on the predicted wall heat fluxes as observed in the investigations concerning natural gas combustion[5,42].

\section{Conclusions}

The present work provides a detailed analysis and an unsuccessful validationattempt of a modern industrially relevant (i.e. computationally manageable) effervescent spray modelling approach. The investigated application is a 1 MW swirling flame of light fuel oil in a large-scale water-cooled laboratory furnace. Data for validation include spray characteristics in six locations along the spray radius at $150 \mathrm{~mm}$ axial distance from the nozzle and distribution of local heat flux along furnace walls. The following conclusions were drawn:

- The measured number-based drop size distribution of effervescent spray is unimodal around the axis and bimodal in the external part of the spray. Volume-based distributions are much less smooth and 
rather than bimodality they display irregularities among the larger drops. The volume-based distributions are clearly much more sensitive to the number of measured drops.

- The measurements prove that in effervescent sprays it is insufficient to measure a single total drop size distribution for a given axial position, as the distributions change very significantly in the radial direction. Single SMD value that is often provided in the literature is even less representative.

- Comparisons between predicted and experimentally measured radial drop size distributions show that the spray model implemented in this work based on Lund's primary breakup model [18] and secondary breakup model by Reitz [21] is insufficient to describe the formation of effervescent spray.

- The computational model does not predict the formation of small drops below $30 \mu \mathrm{m}$, which is in contrast with drops down to $3 \mu \mathrm{m}$ observed in the measurements.

- Comparison of the predicted and measured heat loads on furnace walls shows that the real flame is significantly shorter. As predictions for natural gas combustion in the same furnace with a similar gas burner do not display this discrepancy [5], it may be attributed to the deficiencies of the spray model, mainly to the missing small drops below $30 \mu \mathrm{m}$.

- Drop dynamics at the atomizer exit seems to be an important factor that should be reflected by the primary breakup model. Drop size, velocity, and mass flow rate should be functions of the spray angle.

- The $C_{2}$ parameter value in the secondary breakup sub-model [21] is shown to have only little effect on the drop size distributions studied in this case.

- The proposed method of spray model validation by analysing radial (i.e. depending on spray angle) drop size distributions provides valuable insightsand indeed seems to be necessary for effervescent sprays.

\section{Acknowledgement}

The authors gratefully acknowledge financial support of the Ministry of Education, Youth and Sports of the Czech Republic within the framework of project No. 2B08048 "Waste as raw material and energy source" and within the framework of Operational Programme "Research and Development for Innovations" - "NETME Centre - New Technologies for Mechanical Engineering”.

\section{References}

[1] A. Lefebvre, X. Wang, C. Martin, Spray Characteristics of Aerated-Liquid Pressure Atomizers, Journal of Propulsion and Power. 4 (1988) 293-298.

[2] J. Jedelský, M. Jícha, J. Otáhal, J. Katolický, M. Landsmann, Velocity field in spray of twin-fluid atomizers, 21st Sympozium on Anemometry, Proceedings, Prague, Czech Republic, 2007: pp. 67-74.

[3] E. Babinsky, P.E. Sojka, Modeling drop size distributions, Progress in Energy and Combustion Science. 28 (2002) 303-329.

[4] R.R. Hayes, S. Brewster, B.W. Webb, M.Q. McQuay, A.M. Huber, Crown incident radiant heat flux measurements in an industrial, regenerative, gas-fired, flat-glass furnace, Experimental Thermal and Fluid Science. 24 (2001) 35-46.

[5] J. Vondál, J. Hájek, Experimental and numerical analysis of wall heat transfer in non-premixed gas combustor, Chemical Engineering Transactions. 18 (2009) 587-592.

[6] A. Valero, C. Cortés, Ash fouling in coal-fired utility boilers. Monitoring and optimization of on-load cleaning, Progress in Energy and Combustion Science. 22 (1996) 189-200.

[7] V. Kermes, P. Skryja, P. Stehlík, Up to date experimental facility for testing low-NOx burners, Chemical Engineering Transaction. 12 (2007) 549-554.

[8] A. Sadiki, A. Maltsev, B. Wegner, F. Flemming, A. Kempf, J. Janicka, Unsteady methods (URANS and LES) for simulation of combustion systems, International Journal of Thermal Sciences. 45 (2006) 760-773.

[9] X. Jiang, G. Siamas, K. Jagus, T. Karayiannis, Physical modelling and advanced simulations of gas-liquid two-phase jet flows in atomization and sprays, Progress in Energy and Combustion Science. 36 (2010) 131167.

[10] E. Riber, V. Moureau, M. García, T. Poinsot, O. Simonin, Evaluation of numerical strategies for large eddy simulation of particulate two-phase recirculating flows, Journal of Computational Physics. 228 (2009) 539564.

[11] J. Shinjo, A. Umemura, Detailed simulation of primary atomization mechanisms in Diesel jet sprays (isolated identification of liquid jet tip effects), Proceedings of the Combustion Institute. 33 (2011) 2089-2097.

[12] Y. Yan, J. Zhao, J. Zhang, Y. Liu, Large-eddy simulation of two-phase spray combustion for gas turbine combustors, Applied Thermal Engineering. 28 (2008) 1365-1374. 
[13] A.O. Nieckele, M.F. Naccache, M.S.P. Gomes, Combustion performance of an aluminum melting furnace operating with natural gas and liquid fuel, Applied Thermal Engineering. (2010), doi:10.1016/j.applthermaleng.2010.11.003.

[14] L.P. Chin, G. Switzer, R.S.T. Kin, T. Jackson, J. Stutrud, BI-Modal Size Distributions Predicted by Maximum Entropy are Compared with Experiments in Sprays, Combustion Science and Technology. 109 (1995) 35.

[15] L. Qian, J. Lin, H. Xiong, A Fitting Formula for Predicting Droplet Mean Diameter for Various Liquid in Effervescent Atomization Spray, Journal of Thermal Spray Technology. 19 (2010) 586-601.

[16] P.K. Senecal, D.P. Schmidt, I. Nouar, C.J. Rutland, R.D. Reitz, M.L. Corradini, Modeling high-speed viscous liquid sheet atomization, International Journal of Multiphase Flow. 25 (1999) 1073-1097.

[17] C. Weber, Disintegration of Liquid Jets, Z. Angew Math. Mech. 11 (1931) 136-159.

[18] M.T. Lund, P.E. Sojka, A.H. Lefebvre, Effervescent atomization at low mass flow rates. Part I: The influence of surface tension, Atomization and Sprays. 3 (1993) 77-89.

[19] H. Xiong, J. Lin, Z. Zhu, Three-dimensional simulation of effervescent atomization spray, Atomization and Sprays. 19 (2009) 75-90.

[20] G.I. Taylor, The Shape and Acceleration of a Drop in a High Speed Air Stream, Technical Report, In the Scientific Papers of G. I. Taylor, Ed., G. K. Batchelor, University Press, Cambridge, 1963.

[21] R.D. Reitz, Mechanisms of Atomization Processes in High-Pressure Vaporizing Sprays, Atomization and Spray Technology. (1987) 309-337.

[22] S.H. Park, H.J. Kim, H.K. Suh, C.S. Lee, Experimental and numerical analysis of spray-atomization characteristics of biodiesel fuel in various fuel and ambient temperatures conditions, International Journal of Heat and Fluid Flow. 30 (2009) 960-970.

[23] F. Tanner, Development and validation of a cascade atomization and drop breakup model for high-velocity dense sprays, Atomization and Sprays. 14 (2004) 211-242.

[24] S.V. Apte, M. Gorokhovski, P. Moin, LES of atomizing spray with stochastic modeling of secondary breakup, International Journal of Multiphase Flow. 29 (2003) 1503-1522.

[25] V.A. Vuorinen, H. Hillamo, O. Kaario, M. Nuutinen, M. Larmi, L. Fuchs, Effect of Droplet Size and Atomization on Spray Formation: A Priori Study Using Large-Eddy Simulation, Flow Turbulence Combust. (2010).

[26] A. Aliseda, E. Hopfinger, J. Lasheras, D. Kremer, A. Berchielli, E. Connolly, Atomization of viscous and non-newtonian liquids by a coaxial, high-speed gas jet. Experiments and droplet size modeling, International Journal of Multiphase Flow. 34 (2008) 161-175.

[27] M. Tembely, C. Lecot, A. Soucemarianadin, Prediction and Evolution of Drop-Size Distribution for a New Ultrasonic Atomizer, Applied Thermal Engineering. (2010), doi: 10.1016/j.applthermaleng.2010.09.027.

[28] K. Pougatch, M. Salcudean, E. Chan, B. Knapper, A two-fluid model of gas-assisted atomization including flow through the nozzle, phase inversion, and spray dispersion, International Journal of Multiphase Flow. 35 (2009) 661-675.

[29] J. Jedelský, M. Jícha, J. Sláma, J. Otáhal, Development of an Effervescent Atomizer for Industrial Burners, Energy \& Fuels. 23 (2009) 6121-6130.

[30] V. Cleary, P. Bowen, H. Witlox, Flashing liquid jets and two-phase droplet dispersion: I. Experiments for derivation of droplet atomisation correlations, Journal of Hazardous Materials. 142 (2007) 786-796.

[31] J. Jedelský, M. Jícha, J. Sláma, Characteristics And Behaviour Of Multi-Hole Effervescent Atomizers, 19th International Conference on Liquid Atomization and Spray Systems - ILASS Europe, Nottingham, UK, 2004: pp. 521-526.

[32] M. Liu, Y. Duan, T. Zhang, Evaluation of effervescent atomizer internal design on the spray unsteadiness using a phase/Doppler particle analyzer, Experimental Thermal and Fluid Science. 34 (2010) 657-665.

[32] V. Kermes, P. Bělohradský, Testing of gas and liquid fuel burners for power and process industries, Energy. 33 (2008) 1551-1561.

[34] Ansys® Academic Research, Release 12.1, Help System, Ansys FluentDocumentation, Ansys, Inc, Canonsburg, USA, 2009.

[35] J. Broukal, J. Hájek, J. Jedelský, Effervescent atomization of extra-light fuel-oil: Experiment and statistical evaluation of spray characteristics, Proceedings of 23rd European Conference on Liquid Atomization and Spray Systems, Brno, Czech Republic, 2010: pp. 1-10.

[36] T. Shih, W.W. Liou, A. Shabbir, Z. Yang, J. Zhu, A new k- $\varepsilon$ eddy viscosity model for high reynolds number turbulent flows, Computers \& Fluids. 24 (1995) 227-238.

[37] J. Schröder, M. Schlender, P.E. Sojka, V. Gaukel, H.P. Schuchmann, Modeling of drop sizes from effervescent atomization of gelatinized starch suspensions, Proceedings of 23rd European Conference on Liquid Atomization and Spray Systems, Brno, Czech Republic, 2010: pp. 1-7

[38] L. Fu-shui, Z. Lei, S. Bai-gang, L. Zhi-jie, H.J. Schock, Validation and modification of WAVE spray model for diesel combustion simulation, Fuel. 87 (2008) 3420-3427.

[39] A.B. Liu, D. Mather, R.D. Reitz, Modeling the Effects of Drop Drag and Breakup on Fuel Sprays, University 
of Wisconsin-Madison, Engine Research Center, USA, 1993

[40] P.J. O'Rourke, Collective Drop Effects on Vaporizing Liquid Sprays, Los Alamos National Lab., NM (USA), USA, 1981.

[41] P.J. O'Rourke, A.A. Amsden, The TAB method for numerical calculation of spray droplet breakup, Los Alamos National Lab., NM (USA), USA, 1987.

[42] J. Vondál, J. Hájek, Boundary condition evaluation and stability issues in swirling flame gas combustion, 1st International Conference on Computational Methods for Thermal Problems, Napoli, Italy, 2009: pp. 314-317.

[43] B. Magnussen, B. Hjertager, On mathematical modeling of turbulent combustion with special emphasis on soot formation and combustion, Symposium (International) on Combustion. 16 (1977) 719-729.

[44] S. Baek, H. Kim, M. Yu, S. Kang, M. Kim, Application of the extended weighted sum of gray gases model to light fuel oil spray combustion, Combustion Science and Technology. 174 (2002) 37-70.

[45] J. Ströhle, Spectral Modelling of Radiative Heat Transfer in Industrial Furnaces, Shaker Verlag GmbH, Germany, Aachen, Germany, 2004.

[46] J. Broukal, J. Hájek, Wall heat fluxes in swirling combustion of extra-light fuel-oil in large-scale test combustor: Experiment and modelling using Eddy Dissipation Model, Chemical Engineering Transactions. 21 (2010) 1111-1116.

[47] J. Vondál, J. Hájek, V. Kermes, Local wall heat fluxes in swirling non-premixed natural gas flames in largescale combustor: Data for validation of combustion codes, Chemical Engineering Transactions. 21 (2010) 1123-1128.

\section{Figures}

Figure 1Schematics of the effervescent atomization process (reprinted from Jedelský et al [2])

Figure 2Schematics of the spray measurement (dimensions are expressed in $\mathrm{mm}$ )

Figure 3Drop-size distributions based on number and volume at various measurement points and overall distributions; $r$ represents the radial distance of the measurement point form the spray centreline at $150 \mathrm{~mm}$ downstream from the spray nozzle.

Figure 4Combustion test facility

Figure 5Cross-section of the burner (dimensions are expressed in $\mathrm{mm}$ )

Figure 6Geometry of the cylindrical computational domain

Figure 7Geometry of the combustion chamber with air duct and a detail of the mesh in axial cut

Figure 8Minimal and maximal drop diameters (at axial distance $150 \mathrm{~mm}$ )

Figure 9Comparison of measured and computed radial SMD evolution (at axial distance $150 \mathrm{~mm}$ )

Figure 10Plots of number-based drop-size distributions at various radial locations $r$ (at axial distance $150 \mathrm{~mm}$ )

Figure 11Plots of volume-based drop-size distributions at various radial locations $r$ (at axial distance $150 \mathrm{~mm}$ )

Figure 12Overall drop-size distributions (at axial distance $150 \mathrm{~mm}$ )

Figure 13Comparison of measured and computed wall heat fluxes

\section{Tables}

Table 1Experiment parameters 


\begin{tabular}{ll}
\hline Fuel mass flow & $78.48[\mathrm{~kg} / \mathrm{h}]$ \\
Atomizing air mass flow & $7.85[\mathrm{~kg} / \mathrm{h}]$ \\
Gas-Liquid ratio (GLR) & $10 \%[-]$ \\
Combustion air mass flow & $1280\left[\mathrm{~m}^{3} / \mathrm{h}\right]$ \\
Global air equivalence ratio & $1.46[-]$ \\
Fuel density & $820.7\left[\mathrm{~kg} / \mathrm{m}^{3}\right]$ \\
Combustion air temperature & $4\left[{ }^{\circ} \mathrm{C}\right]$ \\
Fuel temperature & $32\left[{ }^{\circ} \mathrm{C}\right]$ \\
Atomizing air temperature & $20\left[{ }^{\circ} \mathrm{C}\right]$ \\
\hline
\end{tabular}




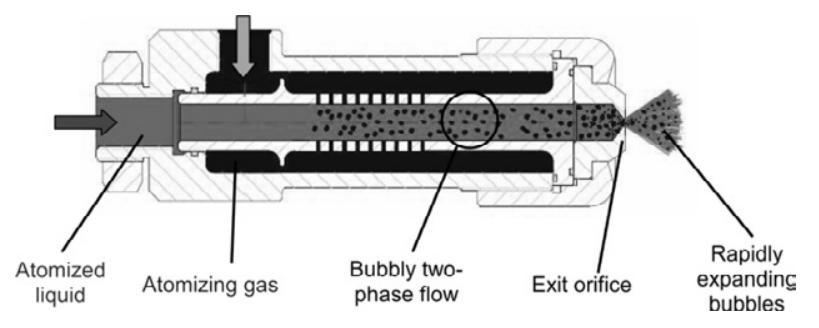




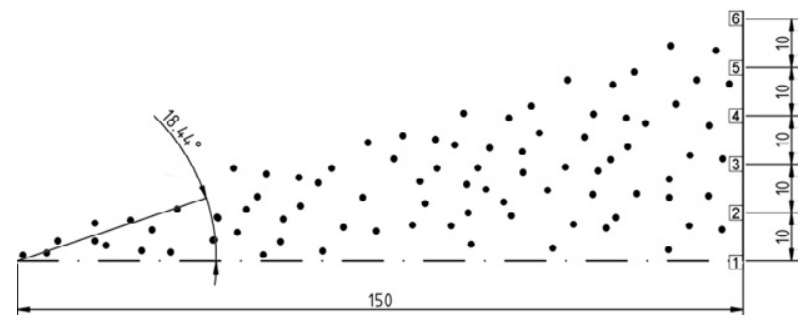



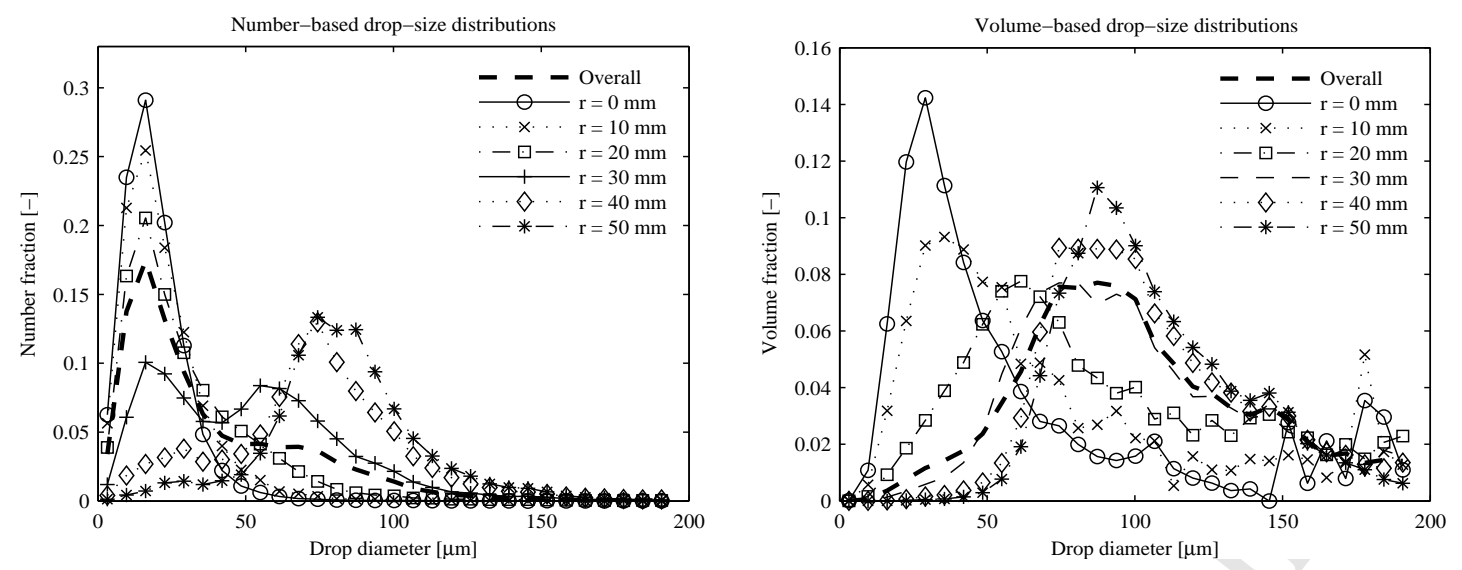


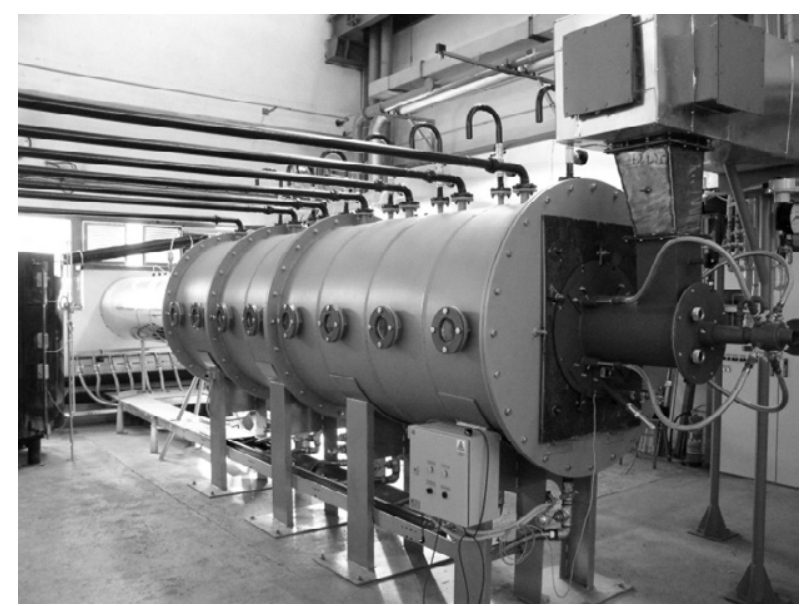


Combustion

air

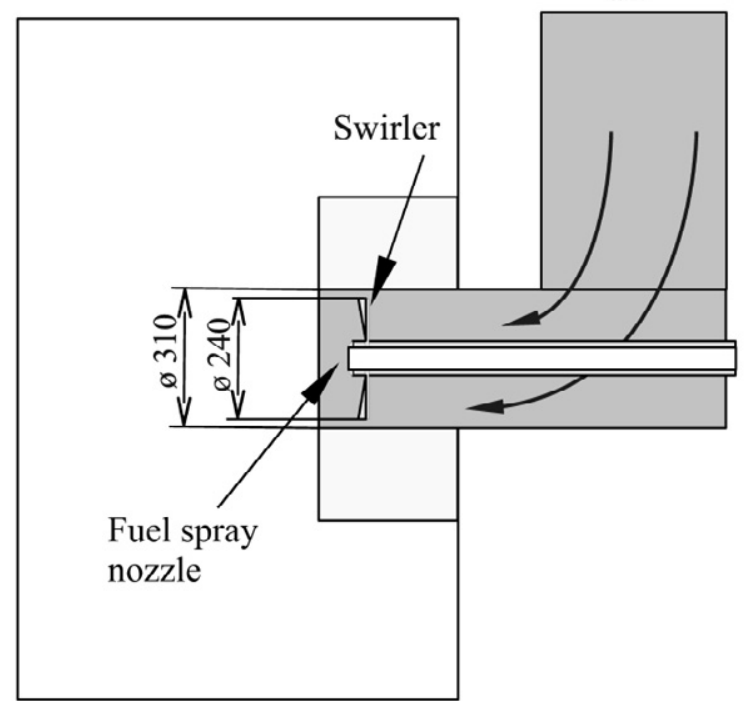




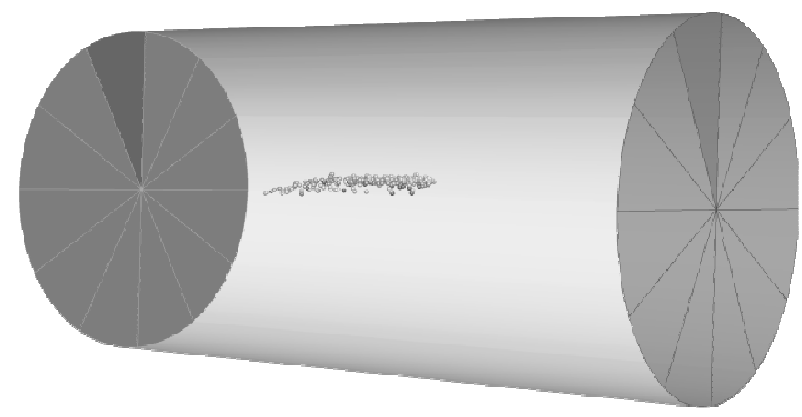



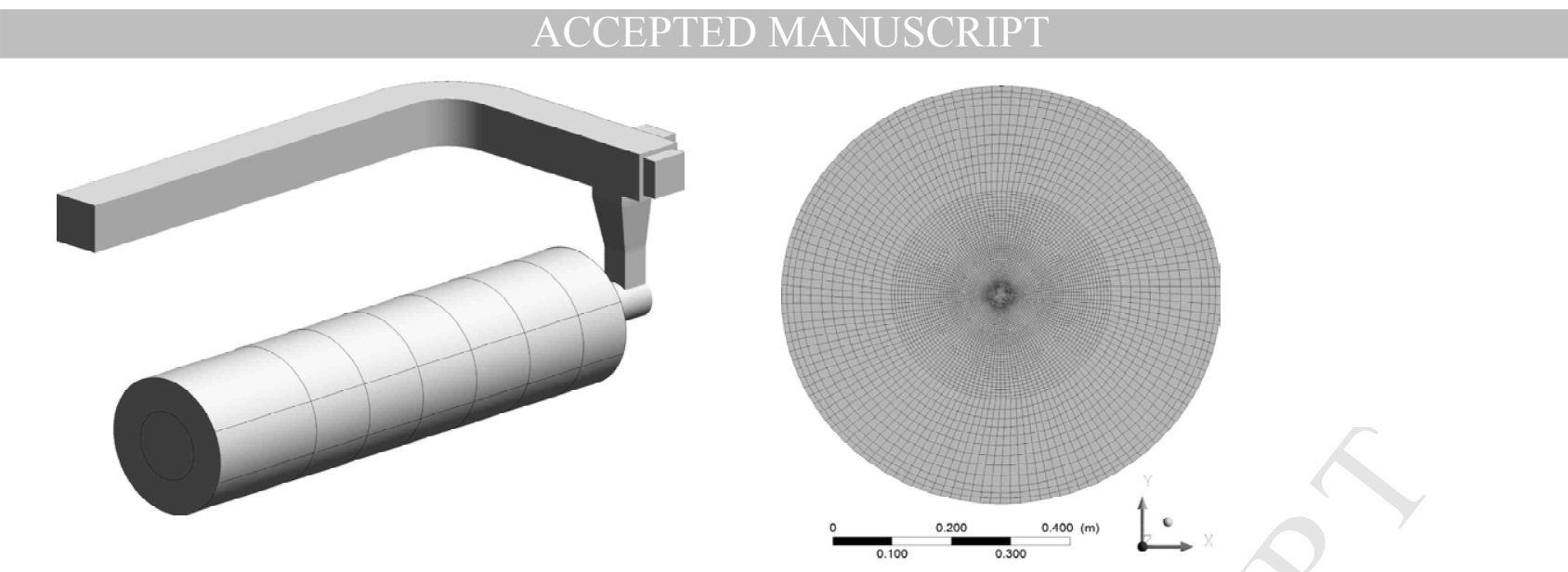


\section{ACCEPTED MANUSCRIPT}
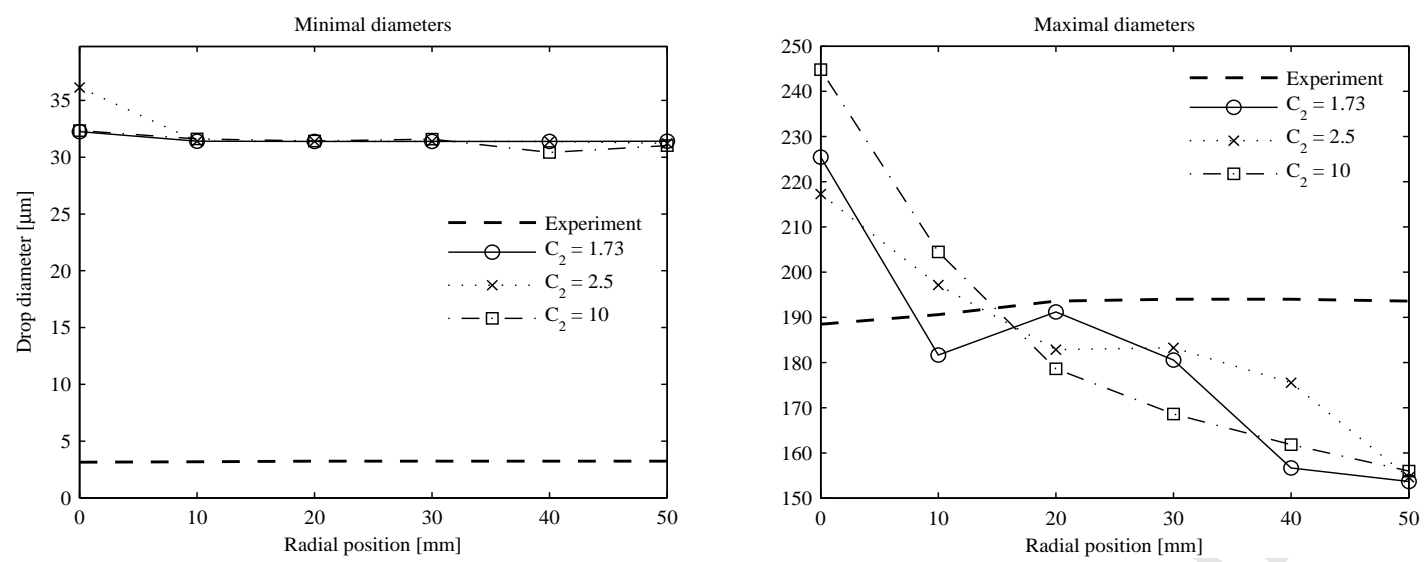


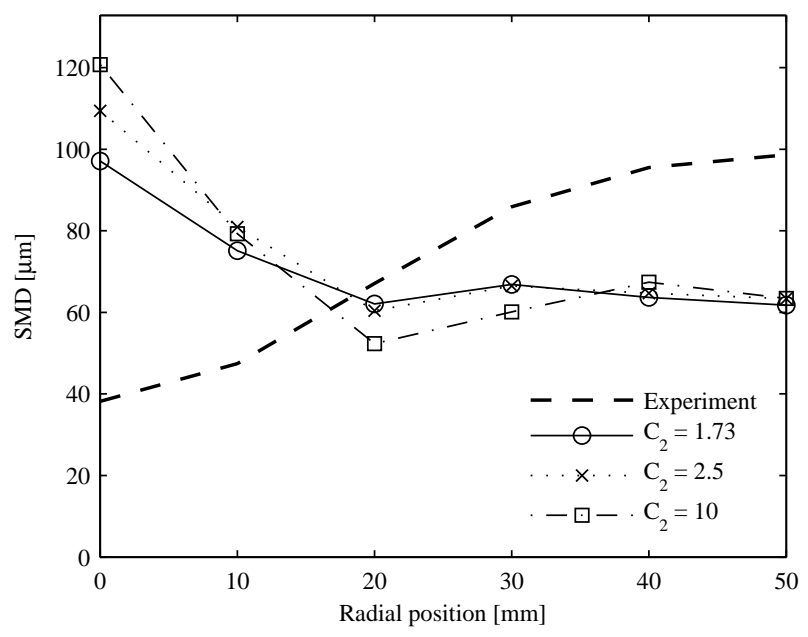



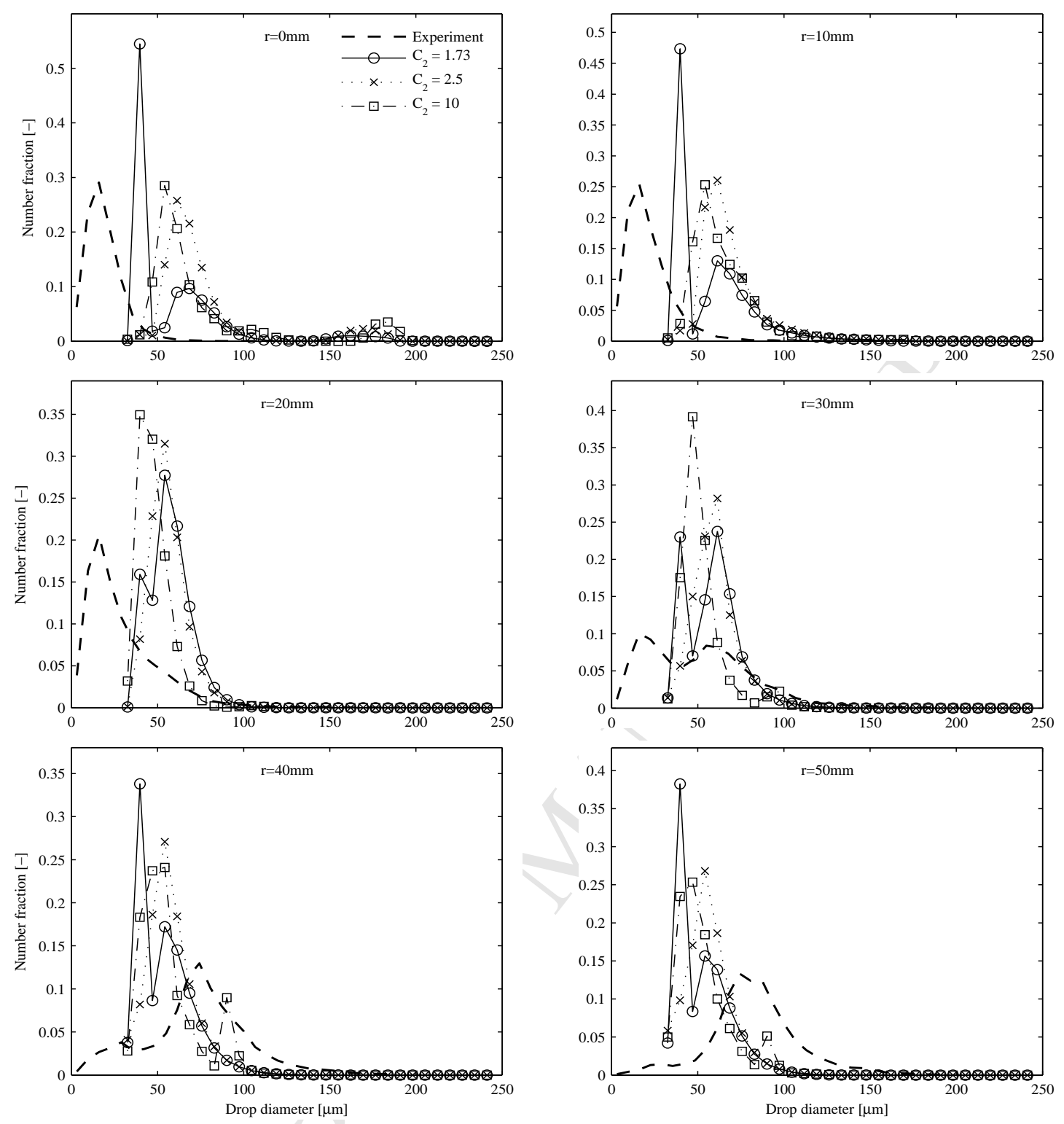

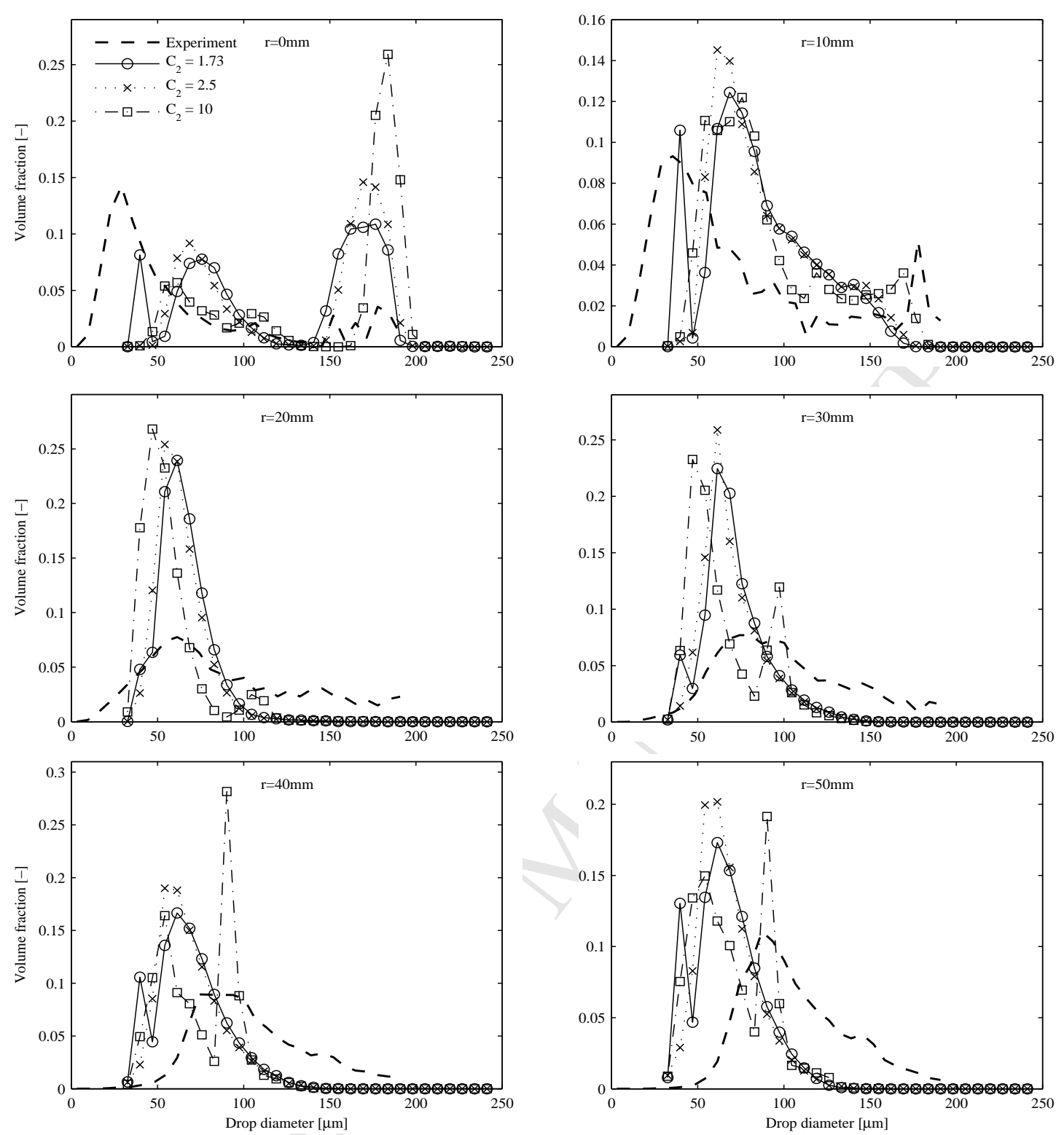

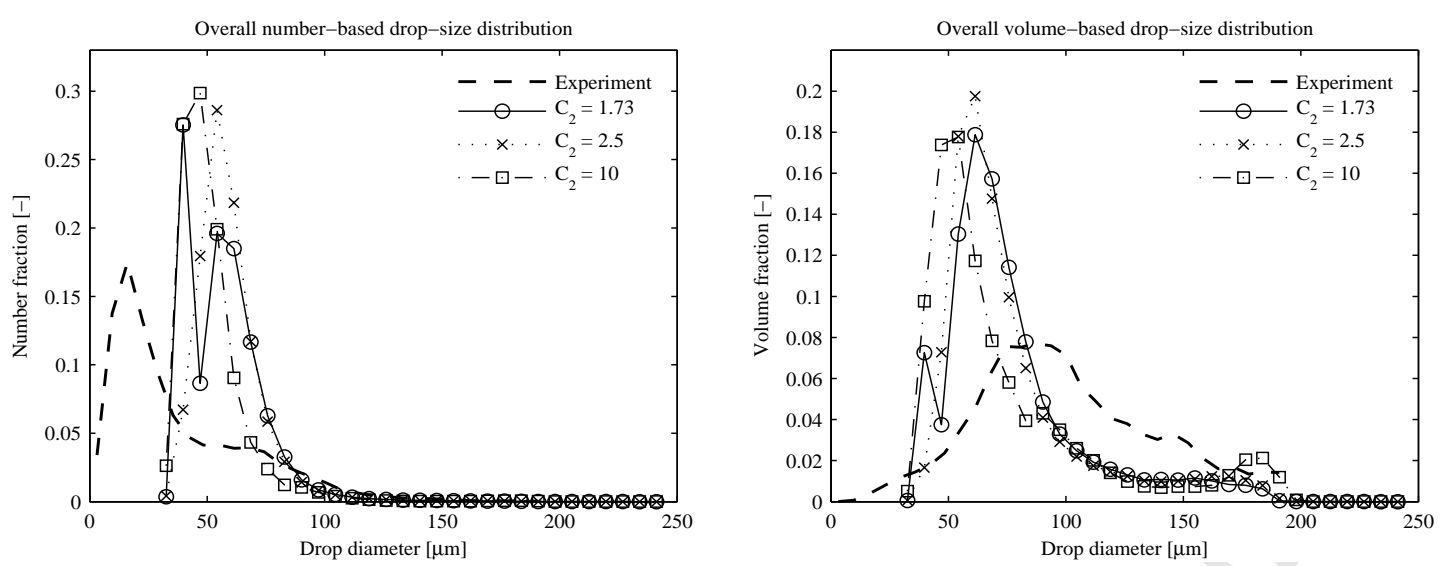


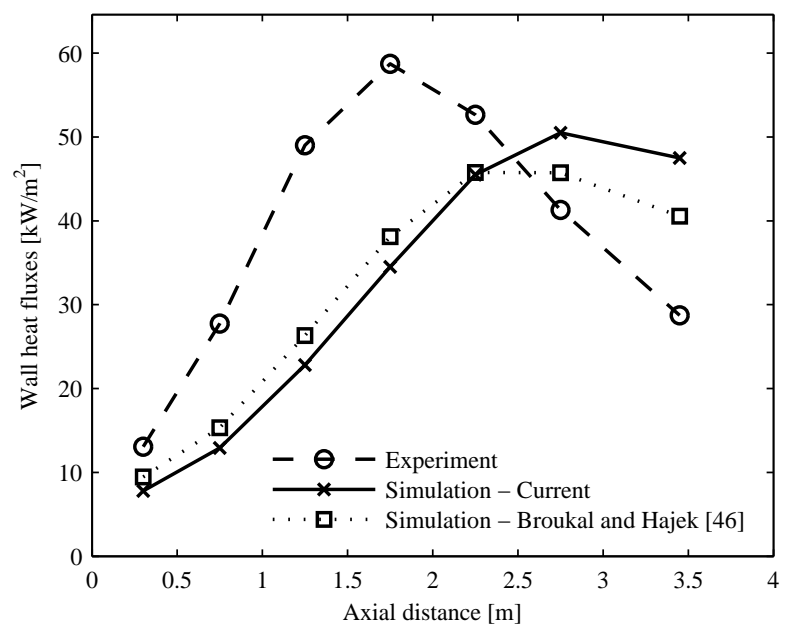

